\title{
Bacterial Production of Hydroxyalkanoates (PHA)
}

\author{
Ester Prados, Sergi Maicas* \\ Department of Microbiology and Ecology, University of Valencia, Spain
}

Copyright $(2016$ by authors, all rights reserved. Authors agree that this article remains permanently open access under the terms of the Creative Commons Attribution License 4.0 International License

\begin{abstract}
The dependence of plastic materials is an increasing problem. Although plastics are very useful for humankind many disadvantages derived from the difficulties linked to recycling and disposal are well known. A feasible alternative is the production and use of bioplastics. These compounds have multiple options at the end of his life that can ensure their safety and efficacy of reuse or recovery. For example, raw materials can be returned to the manufacturer for recycling. Bioplastics synthesized through biotechnology include mainly polyhydroxyalkanoates (PHAs), common lipoidic storage materials accumulated by prokaryotes. Some processes for producing PHAs by fermentation using microorganisms have been developed at a different extent. However, biopolymers (PHA) market is under development, and therefore cannot compete with traditional plastics since manufacturing is still more expensive. In this review we have focused on the study of the production processes of bioplastics where bacteria are present, also describing the scaling to industrial level aspects and future trends.
\end{abstract}

Keywords Bioplastic, Poly-Hydroxyalkanoates, PHA

\section{Introduction}

The dependence of plastic materials in the XXI Century is such that it comes to be difficult to describe a daily situation in which an object made wholly or partly of plastic is not present. However, compared to the many benefits derived from the use of plastic, rises the serious disadvantage linked to the difficulty of recycling and disposal. This difficulty leads to the accumulation of plastic materials in the biosphere as contaminants [1]. For the production of common plastics, non-renewable fossil reserves are used, which contributes to the depletion of natural energy reserves that the planet has, contributing to the increase in greenhouse gases [2]. These conventional materials, by their nature, are stable from the chemical point of view, which means they remain unchanged for long periods of time in the environment. For this reason it is necessary to develop lines of research to obtain new materials capable of replacing them. Fortunately, there is an alternative, via the production of bioplastics. There is a large family of compounds intracellularly accumulated by bacterial species to serve as energy reserve materials and reducing power. These materials have physico-chemical properties similar to those of conventional petrochemical-based plastics, with the particularity that can be biodegraded by microorganisms to finally produce water and carbon dioxide [3, 4]. They are also some limits regarding their biodegradability: sometimes non-degradable materials are required to produce long-lasting products. Fortunately, its duration is sufficient for most packaging we use and throw away every day so its use contributes to reduce the accumulation of wastes.

Among these new materials stand out poly-hydroxyalkanoates (PHA), plastic biopolymers produced by bacteria [3]. The biotechnological production of such bacterial plastic materials (bioplastics) is one of the promising alternatives being considered to reduce petroleum dependency and achieve a reduction of solid waste and emission of gases that cause the greenhouse effect [5]. This possibility is given by the production of biodegradable polymers, from waste carbon source feedstock. The development of biotechnology has enabled, among numerous other applications, find solutions to two of the most serious problems of modern industry of synthetic polymers: a) the ecological problem that arises from the degradation of recalcitrant synthetic polymers, b) the need to produce novel polymers having predetermined unusual physical properties, and that cannot be obtained by chemical synthesis [5].

Moreover these biopolymers have a wide range of applications in fields such as biomedical, cosmetology and industrial applications. The requirement for these substances could reach more than 1 million tones by the next years [6]. The main properties are biodegradability, biocompatibility, ability to resist exposition to light and high temperature. Biocompatibility is perhaps one of the properties of PHA most currently studied, and as a consequence, there have been a lot of developments in the field of biomedical. Moreover, these bioplastics can be introduced into animal tissues without causing alteration of the biochemical homeostasis [7]. However, at present, 
biopolymers (including PHA) market is under development, therefore cannot compete with traditional plastics since manufacturing is still more expensive. The high costs of production and processing is the main obstacle to the expansion of these materials [8-17].

The objective of this review focuses on the study of the production processes of bioplastics where bacteria are present, also describing the scaling to industrial level aspects and future trends.

\section{Polyhydroxyalkanoates: bacterial bioplastics}

The majority of living beings accumulate different substances in reserve when there is excess of resources in their environment $[18,19]$. Some bacteria accumulate reserve substances under certain conditions when the external energy is over the need for the cell to grow and stay. When nutrients become scarce, are used to survive [18]. The component must be used by the cell when the input of external energy is insufficient to maintain the processes of growth, division or cell viability. Under requirement, the compound should be degraded to produce energy assimilable by the cell. From compound backup cell that allows for energy must survive in an unfavorable environment [19].

Polyhydroxyalkanoates (PHA) are some of the most common reserve substances accumulated by prokaryotes [16]. These polymers are accumulated in intracellular granules by numerous species of bacteria, when soil nutrients are essential for growth (such as combined nitrogen, sulfur or phosphates) and there is an excess in carbon source. When external carbon source is exhausted, or if the limiting nutrient is supplied again, the PHA is depolymerized and subsequently metabolized to act as a carbon and energy source. The use of such a polymer is considered a strategy developed by several bacteria to increase their survival in fluctuating environments. They are used as a source of carbon and energy under conditions of scarcity of nutrients, as a source of carbon and energy for entrenchment (Azotobacter sp.) and sporulation (Bacillus sp.), for the degradation of toxic compounds, and as a source of reducing power (protection of nitrogenase complex nitrogen in fixing bacteria, and also as a constituent of the bacterial cytoplasmic membrane [18].

PHA is stored in granules in the cytoplasm. The number of granules depends on the presence of amphiphilic phasins (structural proteins in the pellet surface) [20]. PHA can be accumulated in levels of up to $90 \%$ (dry weight) within the cells, which are also fully biodegradable to $\mathrm{CO}_{2}$ and water through natural microbiological mineralization. The catalysis occurs in many microorganisms by both intra- and extracellular depolymerases [18-20]. PHA depolymerases have a catalytic triad (serine-histidine- aspartic acid) as the active site. The catalytic serine is embedded in a sequence motif (G-X1-X2-S-G), known as lipase box [21].
The PHA polymers are thermoplastic, can be processed on conventional processing equipment and are, depending on their composition, ductile and more or less elastic. Differ in their properties according to their chemical composition (homo- or copolyester, hydroxy fatty acid content). As mentioned, the compounds are polyesters PHA monomers (R)-3-hydroxy acids, generally linear, in which the carboxyl group forms an ester with the hydroxyl group to the next link monomer [22].

So far there have identified more than 150 hydroxyalkanoic acids: saturated, unsaturated, halogenated and aromatic, which are incorporated into the side chain of PHA and in turn change their physical properties, leading them to be used in new technological applications. This variability depends on the type of substrate, the polymerization specificity and different metabolic pathways involving the formation of monomers supplied. The molecular weight of PHA is about $50-100 \mathrm{kDa}$, depending on the nature of the polymer [22]. Due to their structural conformation, Short Chain PHA (SCL) and Long Chain PHA (MCL), differ in their thermoplastic characteristics. SCL are classified as thermoplastics, while MCL, having lower crystallinity and lower melting points are recognized as elastomers. MCL have a breaking elongation curves higher than $100 \%$, while the SCL have a lower rupture elongation curves $(5 \%)$. The characteristics of the environment also affect the production of biopolymers. Several studies have shown the influence of magnetic fields in the yield of microorganisms [22].

\subsection{Chemical Structure}

In general, PHAs are comprised of several repetitions of the same monomer; found nearly 150 different types of monomers incorporated into the PHAs, which include units hydroxyalkanoates substituted with a wide range of groups: alkyl, aryl, alkenyl, cyano, epoxy, ether, and acid groups [23-25]. As a general rule, the composition and physical properties of PHA produced by microorganisms is dependent of the carbon source used [26]. PHA are linear polymers of (R)-3-hydroxy acids in which the carboxyl group of a monomer forms an ester linkage with the hydroxyl group of the next monomer (Figure 1). According to the length of the carbon chain, PHAs are typically divided into three groups:

- SCL: These are (R)-hydroxyalkanoates whose monomers are composed of 3-5 carbons are thermoplastics with a high degree of crystallization; these crystals form stiff making them less flexible.

- MCL: They consist of monomers (chain length of 6-14 C) and may be aliphatic or aromatic. They possess valuable mechanical properties, are hydrophobic, resilient, have a low degree of crystallization (semicrystalline thermoplastic elastomers) and a low melting temperature, like all PHAs are biodegradable and biocompatible. 


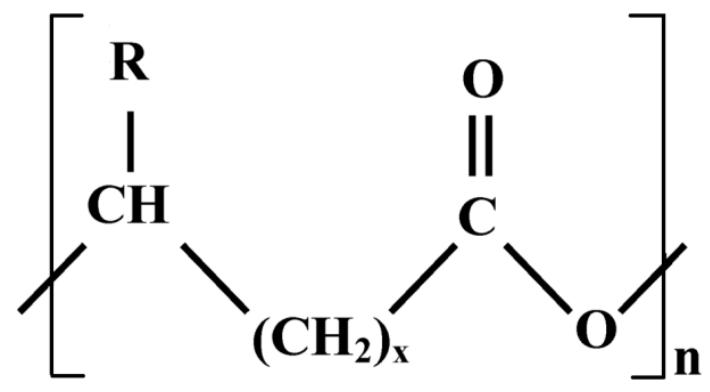

Figure 1. Molecular structure of PHAs. R side chains consist of alkyl groups up to 13 carbon atoms in length, and the number of consecutive $\mathrm{CH}_{2}$ groups in the polymer backbone (x) ranges from 1 to 4 .

- SCL-MCL (Copolymers): Consist of monomers whose chain length is from 4 to $14 \mathrm{C}$, have a range of physical properties depending on the percentage of the molar composition of the different monomers incorporated into the polymer. Copolymers having a low percentage of monomers SCL are more elastomeric [22]. Singh and Mallick have proposed other categories in spite of this, for Pseudomonas aeruginosa cultures: Long-Chain-Length (LCL)-PHAs, SCL-MCL-PHA co-polymer and SCL-LCL-PHA [12-14].

\subsection{Synthesis}

PHA are biodegradable polymers obtained from a wide range of gram-negative and gram-positive bacteria that accumulate them in the cytoplasm, to act as storage materials such as carbon, energy, and reducing power, that are manufactured by these organisms under unbalanced culture conditions $[18,25]$. The most interesting bacteria involved in PHA production are summarized in Table 1. An excess of carbon activates the PHA polymerase enzyme encoded by PhaC. If starvation occurs, PHA depolymerase encoded by PhaZ degrades PHA and R-hydroxyalkanoic acids, to facilitate their use as sources of carbon and energy $[18,27,28]$.

Table 1. Production of poly-hydroxyalkanoates in bacteria

\begin{tabular}{|c|c|c|}
\hline Bacteria & PHA composition & Reference \\
\hline Bacillus cereus & PHB & Ali \& Jamil [29] \\
\hline Bacillus megaterium & PHB & Gouda et al. [30] \\
\hline Bacillus megaterium R11 & PHB & Zhang et al. [31] \\
\hline Bacillus megaterium strain JK4h & PHB & Dhangdhariya et al. [32] \\
\hline Bacillus mycoides RLJ B-017 & PHB & Borah et al. [33] \\
\hline Comamonas testosteroni & PHB & Thakor et al. [34] \\
\hline Cupriavidus necator $\mathrm{H} 16$ & PHB & Batcha et al. [35] \\
\hline Cupriavidus necator H16 & PHB & Obruca et al. [36] \\
\hline Haloferax mediterranei & PHB & Huang et al. [37] \\
\hline Ralstonia eutropha $\mathrm{H} 16$ & PHB & Kahar et al. [38] \\
\hline Recombinant Escherichia coli $\operatorname{arc} \mathrm{A}$ & PHB & Nikel et al. [39] \\
\hline *Recombinant Aeromonas hydrophila 4AK4 & $\mathrm{P}(3 \mathrm{HB}-\mathrm{co}-3 \mathrm{HHx})$ & Tian et al. [40] \\
\hline *Recombinant Ralstonia eutropha H16 strain & P(3HB-co-3HHx) & Kahar et al. [38] \\
\hline *Recombinant $E$. coli $\mathrm{DH} 5 \alpha$ & P(3HB-co-3HHx-co-3HO-co-3HD) & Li et al. [41] \\
\hline Bacillus sp. & $\mathrm{P}(3 \mathrm{HB}-\mathrm{co}-3 \mathrm{HV})$ & Shamala et al. [42] \\
\hline Bacillus sp. 256 & $\mathrm{P}(3 \mathrm{HB}-\mathrm{co}-3 \mathrm{HV})$ & Kumar et al. [43] \\
\hline Brevibacillus invocatus MTCC 9039 & $\mathrm{P}(3 \mathrm{HB}-\mathrm{co}-3 \mathrm{HV})$ & Sankhla et al. [44] \\
\hline Cupriavidus necator & $\mathrm{P}(3 \mathrm{HB}-\mathrm{co}-3 \mathrm{HV})$ & García et al. [45] \\
\hline Halomonas campisalis & $\mathrm{P}(3 \mathrm{HB}-\mathrm{co}-3 \mathrm{HV})$ & Kulkarni et al. [46] \\
\hline Methylobacterium sp. GW2 & $\mathrm{P}(3 \mathrm{HB}-\mathrm{co}-3 \mathrm{HV})$ & Yezza et al. [47] \\
\hline Recombinant $E$. coli XL1 & $\mathrm{P}(3 \mathrm{HB}-\mathrm{co}-3 \mathrm{HV})$ & Yang et al. [48] \\
\hline Serratia ureilytic & $\mathrm{P}(3 \mathrm{HB}-\mathrm{co}-3 \mathrm{HV})$ & Reddy \& Mohan [49] \\
\hline **Pseudomonas aeruginosa MTCC 7925 & P(3HB-co-3HV-co-3HHDco-3HOD) & Singh \& Mallick [14] \\
\hline
\end{tabular}

3HB: 3-hydroxybutyrate, 3HV: 3-hydroxyvalerate, 3HHx: 3-hydroxyhexanoate, 3HO: 3-hydroxyoctanoate, 3HD: 3-hydroxydecanoate, 3HHD: 3-hydroxyhexadecanoic acid, 3HOD: 3-hydroxyoctadecanoic acid, *SCL-MCL-PHA co-polymer producers, **SCL-LCL-PHA co-polymer producers. Modified from Kumar et al. [12]. 


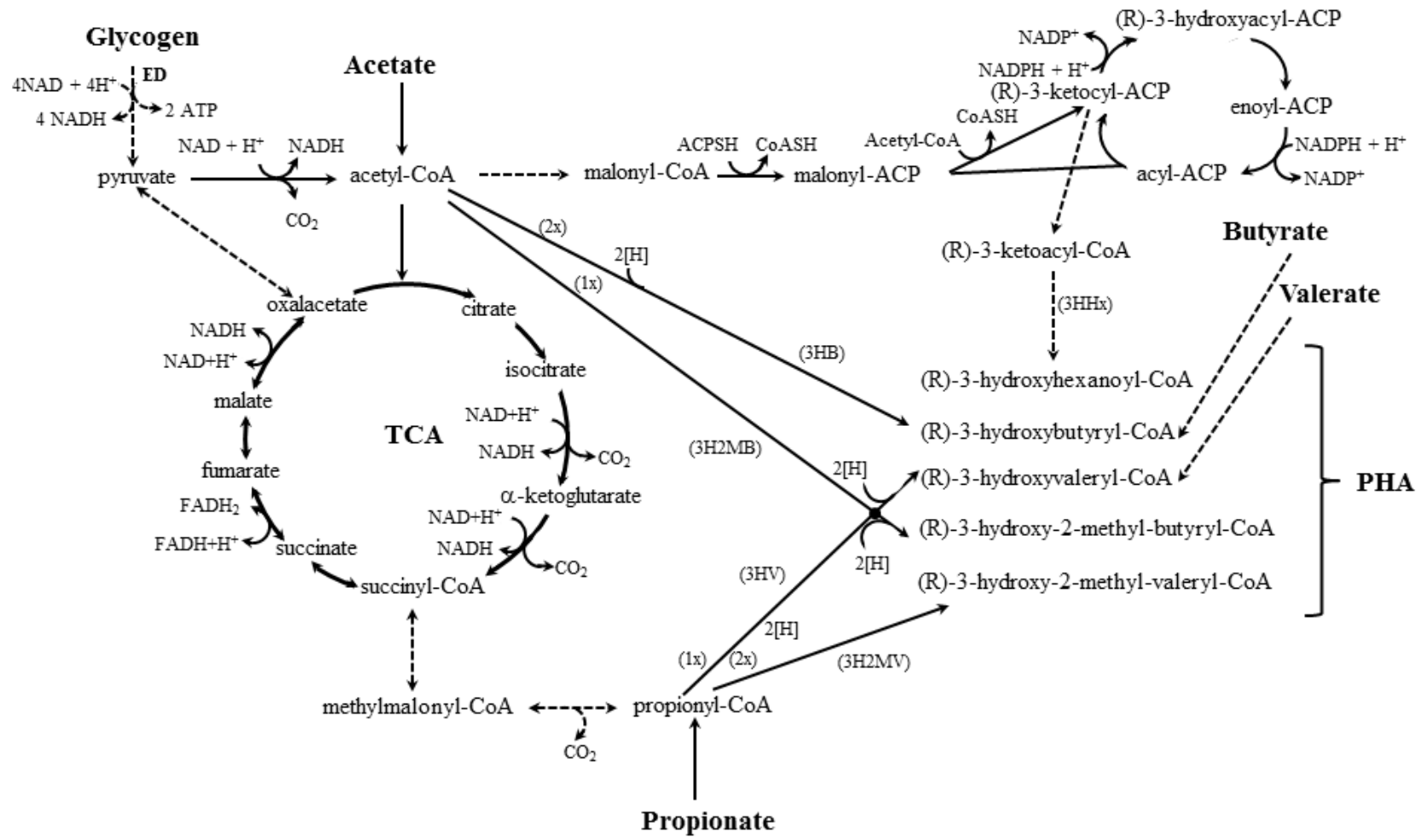

Figure 2. PHA metabolic pathways: ED, Entner-Doudoroff; TCA, tricarboxylic acids

\subsubsection{Metabolism and precursors associated to PHA synthesis}

Polymer synthesis is related to essential metabolic pathways for the cell (Figure 2), because the necessary precursors may be produced in different metabolic pathways as the tricarboxylic acid cycle (TCA), the $\beta$-oxidation of fatty acids and the de novo synthesis of fatty acid, involving central metabolites such as acetyl-CoA and cofactors like NADPH [50]. In the genus Pseudomonas, MCL biosynthesis is closely related to the central metabolic pathways for cell precursors that can provide for polymer synthesis, as the de novo synthesis of fatty acids and $\beta$-oxidation fatty acids [28]. The PhaJ and $P h a G$ genes encoded enzymes to act as a link between these pathways and polymerases, thus providing the monomer required for biosynthesis [51].

\subsubsection{B-oxidation of fatty acids}

In the bacterial metabolism, fatty acids are degraded by B-oxidation by 2 carbon loss in the form of acetyl-CoA. In each cycle the acyl-CoA molecule generated is oxidized to 3-keto-acyl-CoA using (S)-3-hydroxyacyl-CoA as intermediate. The result of this cycle is a fatty acid molecule with n-2 carbon atoms, which can reenter the degradation cycle or be diverted into other pathways [52]. The intermediate (S)-3-hydroxyacyl-CoA cannot be used directly for biosynthesis of PHA, and require the action of the enzyme (R)-enoyl-CoA hydratase (PhaJ), which provides (R)-3-hydroxyacyl-CoA thioester which acts as substrate for the PHA polymerase [53]. There are have been cloned and characterized several R-enoyl-CoA hydratases from various PHA-producing bacteria [52].

\subsubsection{De novo synthesis of fatty acids}

Fatty acid synthesis is carried out by a series of enzymatic steps which can involve the activity of enzyme complexes (FASI) or enzymes with a single catalytic domain (FASII). In the first stage a molecule of acetyl-CoA is carboxylated to form malonyl-CoA, therefore this group is transferred to a small carrier molecule of acyl groups (ACP, acyl carrier protein) to form malonyl-ACP. In a successive process, the required residues are added to rend the final fatty acid [26]. The enzyme (R)-3-hydroxyacyl-ACP-CoA transferase $(P h a G)$ plays an important role by connecting the de novo synthesis of fatty acid with the MCL synthesis. PhaG catalyzes the conversion of (R)-3-hydroxyacyl-ACP to (R)-3-hydroxyacyl-CoA and contributes to the biosynthesis of MCL from gluconate or other non-carbon sources [53, 54].

\subsection{Degradation}

There are several routes for metabolization of degradable polymers, basically: a) thermal degradation: by effect of temperature, b) hydrolytic degradation: due to contact with water, c) photodegradation: by sunlight, and d) biodegradation: made by microorganisms. Degradation is faster when low molecular weight polymers are involved. Higher molecular weight polymers require the combination 
of photosensitive and hydrolyzable functional groups to achieve an effective environmental degradation [27]. PHAs are degraded by two major pathways, one intracellular and other extracellular by PHA-hydrolases and PHA-depolymerases [26, 55]. However, the degradation time of a piece of PHA ranges from a few months to years depending on the plastic composition and environmental conditions [56].

\section{Microbial Production Processes}

To develop a process for producing PHAs by fermentation using microorganisms is necessary to optimize the performance and the purification steps of the polymer, and fundamentally to reduce the cost of the substrates used for their production [55]. Nowadays, there are several processes developed for the production of PHAs by fermentation from inexpensive substrates: in Brazil is produced from molasses and in the United States and Korea from various substrates of plant origin [57]. Research on PHA in recent years aimed at reducing production costs and increase productivity using various strategies. To achieve these objectives is essential to optimize the fermentation process. Recent work has demonstrated the importance of studying the overall response to stress in the development of these processes, noting the need for both basic research and applied to the design of biotechnological processes involving fermentation steps [8, 57]. Bacterial synthesis of PHAs has been described in over 300 species. However, before the selection of microorganisms suitable for the industrial production of PHAs various factors should be considered: a) the ability of the cell to grow on not very expensive carbon sources, the speed or rate of growth, the rate of synthesis of the polymer and the maximum possible polymer accumulated by the cell according to the available substrate. Several studies have proposed equations to predict PHA yield in function of the carbon used, which can be quite useful for preliminary calculations $[57,58]$.

Successful approaches to produce PHA have been proposed for several microorganisms, such as Ralstonia eutropha [6], Rhodobacter [59, 60], Azospirillum rubrum [61], Azotobacter [62], Methylocystis [63], Alcaligenes [64], Leptothrix [65], Pseudomonas [19, 51, 52, 55, 66], Baggiatoa [63], Rhizobium [63] Enterobacter [67] or Bacillus [68]. The isolation of each of the microorganisms used for production of PHAs is directly related if it is native or recombinant. In the first case their identification and selection must be made by microbiological techniques (biochemical tests, morphological), in the second case because these microorganisms have been genetically modified by inserting usually plasmids, identification and selection is done using specific techniques depending on the properties of these plasmids (antibiograms or degradation or specified substrates) [58].

\section{Conclusions}

The problems of traditional plastics waste is a persistent problem. The vast majority of plastic products that are not recycled are discarded in landfills, while others are deposited by wind in non-traditional landfills, like the famous Great Pacific garbage patch. Bioplastics have multiple options at the end of his life that can ensure their safety and efficacy of reuse or recovery. For example, raw materials can be returned to the manufacturer for recycling.

To develop a process for producing PHAs by fermentation using microorganisms is necessary to optimize the performance and ease of purification of the polymer, and fundamentally reduce the cost of the substrates used for their production.

\section{Acknowledgements}

This study was performed at University of València (Spain) as part of the Degree dissertation of E. Prados. English text corrected by Matt Shenton (PRS, Hertfordshire, UK).

\section{REFERENCES}

[1] Cole, M., Lindeque, P., Halsband, C., Galloway, T.S. Microplastics as contaminants in the marine environment: A review. Marine Pollution Bulletin 2011, 62: 2588-2597.

[2] Shimao, M. Biodegradation of plastics. Current Opinion in Biotechnology 2001, 12: 242-247.

[3] Tsui, A., Wright, Z.C., Frank, C.W. Biodegradable polyesters from renewable resources. Annual Review of Chemical and Biomolecular Engineering 2013, 4: 143-170.

[4] Yates, M.R., Barlow, C.Y. Life cycle assessments of biodegradable, commercial biopolymers. A critical review Resources. Conservation and Recycling 2013, 78: 54-66.

[5] Khosravi-Darani, K., Mokhtari, Z.-B., Amai, T., Tanaka, K. Microbial production of poly(hydroxybutyrate) from $\mathrm{C} 1$ carbon sources. Applied Microbiology and Biotechnology 2013, 97: 1407-1424.

[6] Metabolix. Why integrate biopolymers into your conversion process? 2013 (Available at http://www.metabolix.com/prod ucts/bioplymerss)

[7] Bang, D.Y., Kyung, M., Kim, M.J., Jung, B.Y., Cho, M.C., Choi, S.M., Kim, Y.W., Lim, S.K., Lim, D.S., Won, A.J., Kwack, S.J., Lee, Y., Kim, H.S., Lee, B.M. Human risk assessment of endocrine-disrupting chemicals derived from plastic food containers. Comprehensive Reviews in Food Science and Food Safety 2012, 11: 453-470.

[8] Oliveira, F.C., Freire, D.M.G., Castilho, L.R. Production of poly(3-hydroxybutyrate) by solid-state fermentation with Ralstonia eutropha. Biotechnology Letters 2004, 26: 1851-1855. 
[9] Thomson, N., Roy, I., Summers, D., Sivaniaha, E. In vitro production of polyhydroxyalkanoates: Achievements and applications. Journal of Chemical Technology and Biotechnology 2010, 85: 760-767.

[10] Varsha, Y.M., Savitha, R. Overview on polyhydroxyalkanoates: A promising biopol. Journal of Microbial and Biochemical Technology 2011, 3: 99-105.

[11] Cheng, Y., Deng, S., Chen, P., Ruan, R. Polylactic acid (PLA) synthesis and modifications: A review. Frontiers of Chemistry in China 2009, 4: 259-264.

[12] Kumar, A., Srivastava, J.K., Mallick, N., Singh, A.K. Commercialization of bacterial cell factories for the sustainable production of polyhydroxyalkanoate thermoplastics: Progress and prospects. Recent Patents on Biotechnology 2015, 9: 4-21.

[13] Singh, A.K., Mallick, N. Enhanced production of SCL-LCL-PHA co-polymer by sludge-isolated Pseudomonas aeruginosa MTCC 7925 Letters in Applied Microbiology 2008, 46: 350-357.

[14] Singh, A.K., Mallick, N. Exploitation of inexpensive substrates for production of a novel SCL-LCL-PHA co-polymer by Pseudomonas aeruginosa MTCC 7925. Journal of Industrial Microbiology and Biotechnology 2009, 36: 347-354.

[15] Gumel, A.M., Annuar, M.S.M., Chisti, Y. Recent advances in the production, recovery and applications of polyhydroxyalkanoates. Journal of Polymers and the Environment 2013, 21: 580-605.

[16] Tiwari, A., Ramirez, A.M., Jain, R., Saxena, A. Green chemistry for the production of biodegradable polymers as solid substrate and the formation of sustainable biofilm. Key Engineering Materials 2012, 517: 755-762.

[17] Kabilan, S., Ayyasamy, M., Jayavel, S., Paramasamy, G. Pseudomonas sp. as a source of medium chain length polyhydroxyalkanoates for controlled drug delivery: perspective. International Journal of Microbiology 2012, 317828.

[18] Tan, G.A., Chen, C.-L., Li, L., Ge, L., Wang, L., Razaad, I.M.N., Li, Y., Zhao, L., Mo, Y., Wang, J.Y. Start a research on biopolymer polyhydroxyalkanoate (PHA): A review Polymers 2014, 6: 706-754.

[19] Hazer, B., Steinbüchel, A. Increased diversification of polyhydroxyalkanoates by modification reactions for industrial and medical applications. Applied Microbiology and Biotechnology 2007, 74: 1-12.

[20] Verlinden, R.A.J., Hill, D.J., Kenward, M.A., Williams, C.D., Radecka, I. Bacterial synthesis of biodegradable polyhydroxyalkanoates Journal of Applied Microbiology 2007, 102: 1437-1449.

[21] Balaji, S., Gopi, K., Muthuvelan, B. A review on production of poly-ß-hydroxybutyrates from cyanobacteria for the production of bio plastics. Algal Research 2013, 2: 278-285.

[22] Ushimaru, K., Motoda, Y., Numata, K., Tsuge, T. Phasin proteins activate aeromonas caviae polyhydroxyalkanoate (PHA) synthase but not Ralstonia eutropha PHA synthase. Applied and Environmental Microbiology 2014, 80: 2867-2873.

[23] Khanna, S., Srivastava, A.K. Statistical media optimization studies for growth and PHB production by Ralstonia eutropha. Process Biochemistry 2005; 40: 2173-82.

[24] Vincenzini, M., De Philippis, R. Polyhydroxyalkanoates. In: Cohen Z, Ed. Chemicals from Microalgae. USA: Taylor and Francis Inc. 1999, 292-312.

[25] Reddy, C.S.K., Ghai, R., Rashmi, Kalia V.C. Polyhydroxyalkanoates: an overview. Bioresource Technology 2003;87; 137-46.

[26] Knoll, M., Hamm, T.M., Wagner, F., Martinez, V., Pleiss, J. The PHA Depolymerase Engineering Database: A systematic analysis tool for the diverse family of polyhydroxyalkanoate (PHA) depolymerases. BMC Bioinformatics 2009, 10: 89.

[27] González, Y., Meza, J.C., González, O., Córdoba, J.A. Síntesis y biodegradación de polihidroxialcanoatos: plásticos de origen microbiano. Revista Internacional Contaminación Ambiental 2013, 29: 77-115.

[28] Eugenio, L.I., García, P. Luengo, J.M., Sanz, J.M., San Román, J., García, J.L., Prieto, M.A. Biochemical evidence that phaZ gene encodes a specific intracellular medium chain length polyhydroxyalkanoate depolymerase in Pseudomonas putida KT2442 characterization of a paradigmatic enzyme. The Journal of Biological Chemistry 2007, 282:4951-4962.

[29] Ali, I., Jamil, N. Enhanced biosynthesis of poly(3-hydroxybutyrate) from potato starch by Bacillus cereus strain 64-INS in a laboratory-scale fermenter. Preparative Biochemistry Biotechnology 2014; 44: 822-33.

[30] Gouda, M.K., Swellam, A.E., Omar, S.H. Production of PHB by a Bacillus megaterium strain using sugarcane molasses and corn steep liquor as sole carbon and nitrogen sources. Microbiology Research 2001; 156: 201-7.

[31] Zhang, Y., Sun, W., Wang, H., Geng, A. Polyhydroxybutyrate production from oil palm empty fruit bunch using Bacillus megaterium R11. Bioresource Technology 2013; 147: 307-14.

[32] Dhangdhariya, J.H., Dubey, S., Trivedi, H.B., Pancha, I., Bhatt, J.K., Dave, B.P., Mishra, S. Polyhydroxyalkanoate from marine Bacillus megaterium using CSMCRI's Dry Sea Mix as a novel growth medium. International Journal of Biological Macromolecules 2015; 76: 254-61.

[33] Borah, B., Thakur, P.S., Nigam, J.N. The influence of nutritional and environmental conditions on the accumulation of poly- $\beta$-hydroxybutyrate in Bacillus mycoides RLJ B-017. Journal of Applied Microbiology 2002; 92: 776-83.

[34] Thakor, N.S., Patel, M.A., Trivedi, U.B., Patel K.C. Production of poly( $\beta$-hydroxybutyrate) by Comamonas testosteroni during growth on naphthalene. World Journal of Microbiololy and Biotechnology 2003; 19: 185-9.

[35] Batcha, A.F., Prasad, D.M., Khan, M.R., Abdullah, H. Biosynthesis of poly(3-hydroxybutyrate) (PHB) by Cupriavidus necator H16 from jatropha oil as carbon source. Bioprocess and Biosystems Engineering 2014; 37: 943-51.

[36] Obruca, S., Petrik, S., Benesova, P., Svoboda, Z., Eremka, L., Marova, I. Utilization of oil extracted from spent coffee grounds for sustainable production of polyhydroxyalkanoates. Applied Microbiology and Biotechnology 2014; 98: 5883-90.

[37] Huang, T.Y., Duan, K.J., Huang, S.Y., Chen, C.W. Production of polyhydroxyalkanoates from inexpensive extruded rice 
bran and starch by Haloferax mediterranei. Journal of Industrial Microbiology and Biotechnology 2006; 33:701-6.

[38] Kahar, P., Tsuge, T., Taguchi, K., Doi, Y. High yield production of polyhydroxyalkanoates from soybean oil by Ralstonia eutropha and its recombinant strain. Polymers Degradation and Stabilization 2004; 83: 79-86.

[39] Nikel, P.I., Pettinari, M.J., Galvagno, M.A., Méndez, B.S. Poly(3-hydroxybutyrate) synthesis from glycerol by a recombinant Escherichia coli arcA mutant in fedbatch microaerobic cultures. Applied Microbiology and Biotechnology 2008; 77: 1337-43.

[40] Tian, S.J., Lai, W.J., Zheng, Z., Wang, H.X., Chen, G.Q. Effect of over-expression of phasin gene from Aeromonas hydrophila on biosynthesis of copolyesters of 3-hydroxybutyrate and 3-hydroxyhexanoate. FEMS Microbiology Letters 2005; 244: 19-25.

[41] Li, Q.A., Chen, Q.A., Li, M.J., Wang, F.S., Qi, Q.S. Pathway engineering results the altered polyhydroxyalkanoates composition in recombinant Escherichia coli. New Biotechnology 2011, 28: 92-5.

[42] Shamala, T.R., Vijayendra, S.V., Joshi, G.J. Agroindustrial residues and starch for growth and coproduction of polyhydroxyalkanoate copolymer and $\alpha$-amylase by Bacillus sp. CFR-67. Brazilian Journal of Microbiology 2012; 43:1094-102.

[43] Kumar, P.K.A., Shamala, T.R., Kshama, L., Prakash, M.H., Joshi, G.J., Chandrashekar, A., Latha Kumari, K.S., Divyashree, M.S. Bacterial synthesis of poly(hydroxybutyrate-co-hydroxyvalerate) using carbohydrate-rich mahua (Madhuca sp.) flowers. Journal of Applied Microbiology 2007; 103: 204-9.

[44] Sankhla, S.S., Bhati, R., Singh, A.K., Mallick, N. Poly(3hydroxybutyrate-co-3- hydroxyvalerate) co-polymer production from a local isolate, Brevibacillus invocatus MTCC 9039. Bioresource Technology 2010; 101: 1947-53.

[45] García, I.L., López, J.A., Dorado, M.P., Kopsahelis, N., Alexandri, M., Papanikolaou, S., Villar, M.A., Koutinas, A.A. Evaluation of by-products from the biodiesel industry as fermentation feedstock for poly(3-hydroxybutyrate-co-3hydroxyvalerate) production by Cupriavidus necator. Bioresource Technology 2013; 130: 16-22.

[46] Kulkarni, S.O., Kanekar, P.P., Nilegaonkar, S.S., Sarnaik, S.S., Jog, J.P. Production and characterization of a biodegradable poly (hydroxybutyrate-co-hydroxyvalerate) (PHB-co-PHV) copolymer by moderately haloalkalitolerant Halomonas campisalis MCM B-1027 isolated from Lonar Lake, India. Bioresource Technology 2010; 101: 9765-71.

[47] Yezza, A., Fournier, D., Halasz, A., Hawari, J. Production of polyhydroxyalkanoates from methanol by a new methylotrophic bacterium Methylobacterium sp. GW2. Applied Microbiology and Biotechnology 2006; 73: 211-8.

[48] Yang, J.E., Choi, Y.J., Lee, S.J, Kang, K.H., Lee, H., Oh, Y.H., Lee, S.H., Park, S.J., Lee, S.Y. Metabolic engineering of Escherichia coli for biosynthesis of poly(3hydroxybutyrate-co-3-hydroxyvalerate) from glucose. Applied Microbiology and Biotechnology 2014; 98: 95-104.

[49] Reddy, M.V., Mohan, S.V. Polyhydroxyalkanoates production by newly isolated bacteria Serratia ureilytica using volatile fatty acids as substrate: Bio-electro kinetic analysis. Journal of Microbial Biochemistry and Technology 2015; 7: 1 .

[50] Aldor, S.S., Keasling, J.D. Process design for microbial plastic factories: metabolic engineering of polyhydroxyalkanoates. Current Opinion in Biotechnology 2003, 14: 475-83.

[51] Nomura, C.T., Taguchi, K., Taguchi, S., Doil, Y. Coexpression of genetically engineered 3-ketoacyl-ACP synthase III (fabH) and polyhydroxyalkanoate synthase (phaC) genes leads to short-chain-lengthmedium-chain-length polyhydroxyalkanoate copolymer production from glucose in Escherichia coli JM109. Applied and Environmental Microbiology 2004, 70: 999-1007.

[52] Tsuge, T. Metabolic improvements and use of inexpensive carbon sources in microbial production of polyhydroxyalcanoaltes. Journbal of Bioscience and Bioengineering 2002, 94: 579-84.

[53] Fiedler, S., Steinbüchel, A., Rehm, B.H. The role of the fatty acid $\beta$-oxidation multienzyme complex from Pseudomonas oleovorans in polyhydroxyalkanoate biosynthesis: Molecular characterization of the fadBA operon from $P$. oleovorans and of the enoyl-CoA hydratase genes phaJ from $P$. oleovorans and Pseudomonas putida. Archives of Microbiology 2002, 178: $149-60$.

[54] Solaiman, D.K.Y., Ashby, R.D., Crocker, N., Lai, B.H., Zerkowski, J.A. Rhamnolipid and poly(hydroxyalkanoate) biosynthesis in 3-hydroxyacyl-ACP: CoA transacylase (phaG)-knockouts of Pseudomonas chlororaphis. Biocatalysis and Agricultural Biotechnology 2014, 3: 159-66.

[55] Mao, H., Jiang, H., Su, T., Wang, Z. Purification and characterization of two extracellular polyhydroxyalkanoate depolymerases from Pseudomonas mendocina. Biotechnology Letters 2013, 35: 1919-24.

[56] Voinova, O., Gladyshev, M., Volova, T.G. Comparative study of PHA degradation in natural reservoirs having various types of ecosystems. Macromolecular Symposia 2008, 269: 34-37.

[57] Almeida, A., Ruiz, J.A., López, N.I., Pettinari, M.J. Universidad de Buenos Aires. Bioplásticos: una alternativa ecológica. Revista QuímicaViva 2004, 3.

[58] Ortiz García, E. Obtención, aislamiento e identificación de cepas bacterianas presuntas productoras de poli-ß-hidroxialcanoatos (PHAs). 2009. PhD dissertation thesis. Universidad Veracruzana (Mexico)

[59] Kemavongse, K., Prasertsan, P., Upaichit, A., Methacanon, P. Poly- $\beta$-hydroxyalkanoate production by halotolerant Rhodobacter sphaeroides U7. World Journal of Microbiology and Biotechnology 2008, 24: 2073-85.

[60] Arumugam, A., Sandhya, M., Ponnusami, V. Biohydrogen and polyhydroxyalkanoate co-production by Enterobacter aerogenes and Rhodobacter sphaeroides from Calophyllum inophyllum oil cake. Bioresource Technology 2014, 164: 170-6.

[61] Jin, H., Nikolau, B.J. Evaluating PHA productivity of bioengineered Rhodosprillum rubrum. PLoS ONE 2014, 9: e96621.

[62] Segura, D., Cruz, T., Espín, G. Encystment and alkylresorcinol production by Azotobacter vinelandii strains impaired in poly- $\beta$-hydroxybutyrate synthesis. Arch Microbiology 2003, 179: 437-43.

[63] Snell, K.D., Peoples, O.P. PHA bioplastic: A value-added coproduct for biomass biorefineries. Biofuels, Bioproducts 
and Biorefining 2009, 3: 456-67.

[64] Choi, G.G., Kim, H.W., Rhee, Y. Enzymatic and non-enzymatic degradation of poly (3-Hydroxybutyrate-co-3 -Hydroxyvalerate) copolyesters produced by Alcaligenes sp. MT-16. Journal of Microbiology 2006, 42: 346-352

[65] Elbanna, K., Lütke-Eversloh, T.J., Lendrossek, D., Luftmann, H., Steinbüchel, A. Studies on the biodegradability of polythioester copolymers and homopolymers by polyhydroxyalkanoate (PHA)-degrading bacteria and PHA depolymerases. Archives of Microbiology 2004, 182: 212-25.

[66] Catone, M.V., Ruiz, J., Castellanos, M., Segura, D. High polyhydroxybutyrate production in Pseudomonas extremaustralis is associated with differential expression of horizontally acquired and core genome polyhydroxyalkanoate synthase genes. PLoS ONE 2014, 9: e98873.

[67] Vinish, V., Sangeetha, S.H., Aravind, J., Kanmani, P., Sathiskumar, T. Optimizing the nutrient feeding strategy for PHA production by a novel strain of Enterobacter sp. International Journal of Environmental Science and Technology2015, 12: 2757-64.

[68] Tsuge, T., Hyakutake, M., Mizuno, K. Class IV polyhydroxyalkanoate (PHA) synthases and PHA-producing Bacillus. Applied Microbiology and Biotechnology 2015, 99: 6231-40. 